\title{
A review on the recent development of solar absorption and vapour compression based hybrid air conditioning with low temperature storage
}

\author{
D. N. Noor ${ }^{1, a}$, A. Arshad 1 , Z. Azran², H. Ibrahim¹ and F. Basrawi ${ }^{1}$ \\ ${ }^{1}$ Energy Sustainability Focus Group (ESFG), Faculty of Mechanical Engineering, Universiti Malaysia Pahang, 26600 Pekan, Pahang, \\ Malaysia \\ ${ }^{2}$ Faculty of Allied Health Science, International Islamic University Malaysia, 25200 Kuantan, Pahang, Malaysia
}

\begin{abstract}
Conventional air conditioners or vapour compression systems are main contributors to energy consumption in modern buildings. There are common environmental issues emanating from vapour compression system such as greenhouse gas emission and heat wastage. These problems can be reduced by adaptation of solar energy components to vapour compression system. However, intermittence input of daily solar radiation was the main issue of solar energy system. This paper presents the recent studies on hybrid air conditioning system. In addition, the basic vapour compression system and components involved in the solar air conditioning system are discussed. Introduction of low temperature storage can be an interactive solution and improved economically which portray different modes of operating strategies. Yet, very few studies have examined on optimal operating strategies of the hybrid system. Finally, the findings of this review will help suggest optimization of solar absorption and vapour compression based hybrid air conditioning system for future work while considering both economic and environmental factors.
\end{abstract}

\section{Introduction}

Ever since human beings exist, they require energy as part of their living needs. Today, energy are generated mostly from non renewable sources such as oil, natural gas and coal which cannot be replenished. Currently, fossil fuel considered and fully utilizable form of prominent sources of generating energy [1]. Thus, world environmental issues arise and lead to global warming [2]. On the other hand, exploration of potential renewable energy such as solar, wind, hydropower, biomass and geothermal dramatically increase in order to recoup balance of common energy sources.

Current technology of air conditioning basically uses direct electricity from the national service provider-in other words it takes into account of fossil fuel burning in the power plant. Generally, this technology do contribute to emission of hazardous greenhouse gasses to environment [3, 4]. Furthermore, the world climate changes especially in tropical region require high demand on cool range indoor temperature for daily comfort; either residential, industrial, or commercial buildings.

The development in the field of space cooling has led to a renewed interest in renewable energy. There have been several studies in the literature reporting utilization of renewable energy especially solar energy primarily for cooling purpose. There is a large volume of published study describing hybrid solar air conditioning in the past decade. Numerous studies have attempted to explain performance analysis [5-7], economic assessment [8] and environmental assessment separately as part of the indicator of hybrid solar air conditioning. However, to the best of author's knowledge, there are few studies relating to operation strategy. In fact, there is no study focusing on operation strategy while considering all indicators. The goal of this study is to review available operation strategies comprehensively in order to get optimal analysis.

\section{Vapour compression systems}

Vapour-compression system is widely used for large scale cooling application in Malaysia. In fact, conventional air conditioning contributes to almost 50\% of the total energy usage especially in commercial and residential buildings [9].

Figure 1 shows the common components of vapour compressor system which consists of condenser, expansion valve, evaporator and compressor. The cycle operates by circulating the high refrigerant liquid to the expansion valve. Here, it will expand and flows in a more regulated manner. Then, it passes to the evaporator and pressure is reduced. Once the refrigerant is vaporised, it

a Corresponding author: mfirdausb@ump.edu.my 
will move to the compressor. The compressor will compress the vapour into smaller volume thus increasingly the pressure. The high pressure refrigerant vapour now passes into the condenser and condenses back to liquid state and the cycle will repeat again.

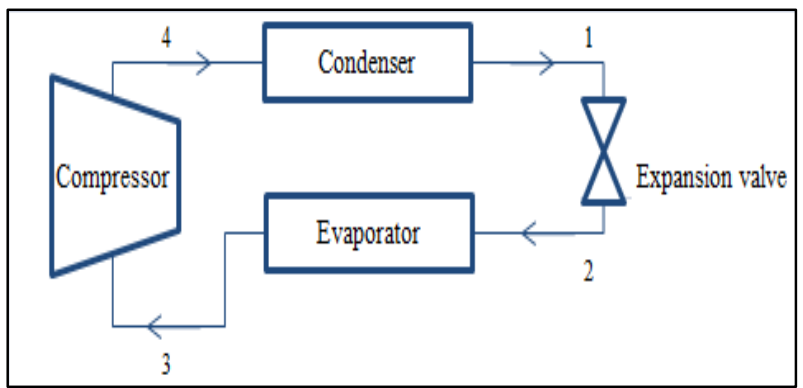

Figure 1. Vapour compressor cycle [10]

Common types of vapour compression system in the market place are wall mounted and ceiling mounted. Usually the wall mounted is able to serve small cooling load (from $1 \mathrm{Hp}$ up to maximum $2.5 \mathrm{Hp}$ ) and efficiently to cool a single room in residential buildings. The flexibility of installation gives advantage for maintenance works. Current models have such good features including less noise by using inverter technology which also improves its efficiency [11, 12]. For ceiling mounted type, it is purposely designed for large scale usage (maximum up to $8 \mathrm{~kW}$ ) especially in commercial and industrial buildings. The latest technology shows that it can distribute evenly cool air to four different directions in a room. Some units have self timer which can be controlled upon necessity thus can save the monthly power bill. Furthermore, optimum setting from maximum to minimum can be matched to current load, which affected by number of people present and initial room temperature [13]. From previous study, scenario in Malaysia shows dramatic growth in the number of common air conditioners from 253,399 in 1991 to approximately increase to $1,511,276$ units in the year 2020, as forecast by Mahlia et al. [14].

\section{Solar air conditioning systems}

In 2014, the national electricity provider (TNB) [15] had increased the electricity tariff and the increase had to some extend burdened the residential and commercial consumers. This had contributed to solar energy interest as the main on-site renewable energy source for cooling purpose and at the same time can save monthly electric bill. Previous studies proved that solar air conditioning could cover energy demand in buildings depending on local climatic conditions and types of building [16]. Solar air conditioning application has progressed considerably over the past years as a result of efforts toward environmental protection and developments in overall systems significantly.

Figure 2 presents the general configuration of solar air conditioning system. Basically, solar energy was harvest by solar collector; flat plate collector or evacuated tube collector and hot water will produce. It will circulate to absorption chiller as chiller needs heat to operate. For basic absorption chiller, chilled water can be produce as low as $6 \mathrm{oC}$. Chilled water will be stored in storage tank and fan coil unit will circulate cool air into buildings.

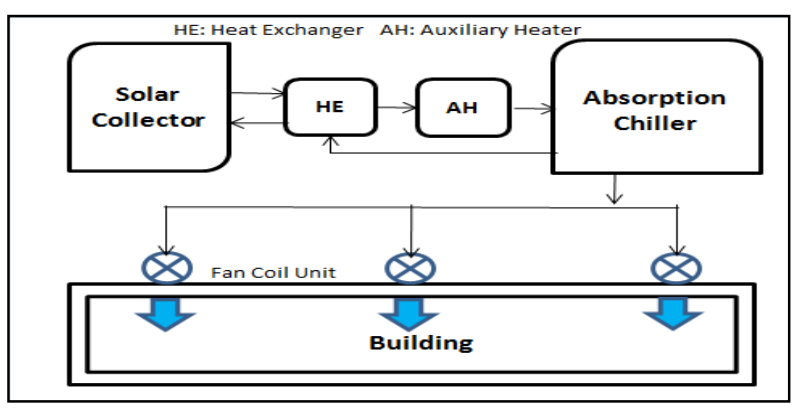

Figure 2. Solar air conditioning system

However, still limited research of solar air conditioning and project development in Malaysia. In Malaysia, the first green building is Greentech Sdn Bhd, located in Bangi which utilized the solar energy for both heating and cooling purpose [17]. Furthermore, commercial buildings in Malaysia such as Ikhasas Sdn Bhd and SDC Sdn Bhd implemented solar energy using solar collector for cooling purpose [18]. For residential application, this can be categorized as small scale project under KeTTHA provision did attract people in urban area to involve by installing the flat plate collector on their roof house [19]. In addition, national service provider in Malaysia (TNB) had offer an incentive to residents who are involved in this project [15]. Therefore, Malaysia have such a great potential in future on exploitation of solar technology due to availability of solar radiation and at the same time giving a new direction on utilization of renewable energy.

\subsection{Solar Collector}

\subsubsection{Flat plate collector}

A flat plate solar collector is one of main type solar collectors in marketplace nowadays. First invention of flat plate is to fulfil the demand on solar water heating system and later had been used for the development of solar air conditioning. Basically, flat plate collectors consist of an absorber, a transparent cover, a frame and insulation as Figure 3. Transparent cover is usually made from an iron-poor solar safety glass as it transmits a great amount of the short-wave light spectrum.

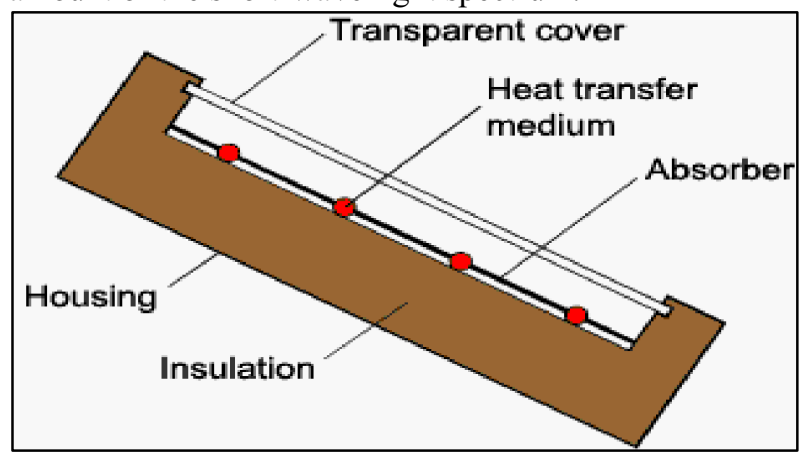

Figure 3. Components of flat plate collector [20] 
Simultaneously, only very small amount of heat emitted by the absorber will escape through cover (greenhouse effect). In addition, the transparent cover prevents wind and breezes from carrying the collected heat away by convection process. Together with the frame, the cover protects the absorber from adverse weather conditions including rain and snow. Commonly, typical frame materials made from aluminum and galvanized steel and fiberglass-reinforced plastic.

The insulation helps to reduce heat loss through conduction. Insulation materials usually are polyurethane foam or mineral wool, but sometimes mineral fiber insulating materials like glass wool, rock wool, glass fiber or fiberglass are used.

\subsubsection{Evacuated tube collector (ETC)}

Solar hot water system has come a long way in the last decade, particularly with the introduction of evacuated tube collectors that are rapidly becoming the preferred option over flat plate systems. Its operate by capturing sunlight much better than flat plate as they have a vacuum space in the tubes and reduce heat losses to the environment [21]. Other than that, tubes are durable and cheaply for replacement. It's proven require smaller roof area but provide greater performance.

The basic components of evacuated tube collector in Figure 4 are shown. Main component is evacuated tube, heat pipe, manifold and header pipe.

Evacuated tube absorbs solar energy and its vacuum area between two layers glass will prevent the heat loss by convection. Heat will transfer to heat pipe which made from copper, then transfer into header pipe (manifold). The sealed metal heat pipes contain a small amount of fluids below atmospheric pressure. The low pressure fluids evaporate causing the hot gas to rise up by convection process. Then the condensed fluid falls down by gravity, so the process can start again. Due to ETC design are capable of collecting solar energy from different angles, its become most efficient solar thermal collector and commonly used for cooking, commercial building, water heating, solar cooling technologies and electric power generation [22].

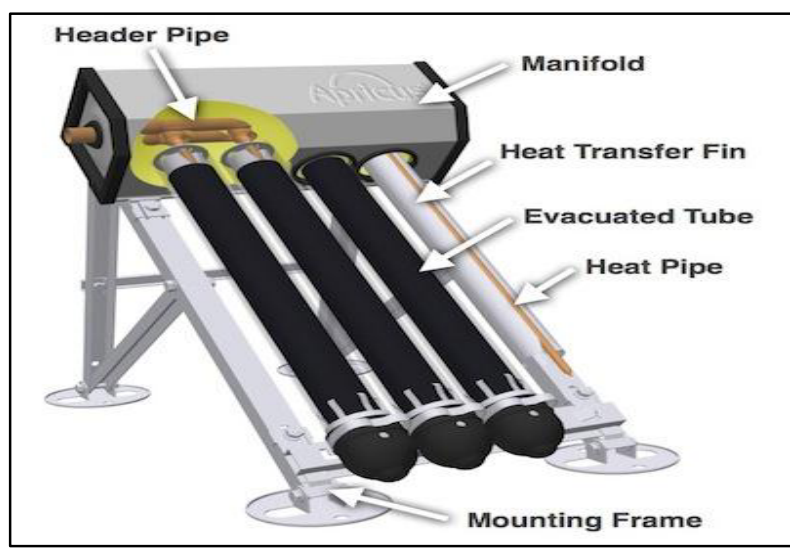

Figure 4. Components of evacuated tube collector [20]
The application of ETC in air conditioning system were studied and proven that efficiency of ETC become maximum when intensity of solar radiation is maximum [23]. However, lack of research on solar air conditioning using evacuated tube collector compared using flat plate system due to ETC substantially more expensive (at 511,29 - 1278,23 Euro $/ \mathrm{m}^{2}$ collector surface) than flat plate collectors $\left(153,34\right.$ to 613,55 Euro $\left./ \mathrm{m}^{2}\right)$ [20].

\subsection{Absorption Chiller}

Absorption chiller use heat typically in the form of steam, hot water or through the direct combustion of natural gas as their sources while most vapour compression chillers utilize electricity to operate. There are two different fluids are used which are refrigerant and an absorbent. These fluids have high affinity which means one will dissolve easily in the other. Water usually been used as refrigerant because of its characteristic to change easily from liquid to vapour state. However, a conventional chiller uses a mechanical means to compress and transport the refrigerant vapor to the condenser, while an absorption chiller depends on a thermo-chemical process involving non toxic solution such as lithium bromide and water to establish the different pressure in mechanical compression. Thus, installation an efficient low temperature driven-sorption machines [24-28] might could be an opportunity to cut down initial investment of overall solar absorption system.

There are few types of commercial absorption chillers in market such as gas operated absorption chiller, steam operated absorption chiller and hot water operated absorption chiller. Then, it can be categorized to direct fired steam, single effect and double effect. Most economic system is direct fired because it has the simplest working principle and suitable for nominal industrial cooling load range between $350 \mathrm{~kW}-1000 \mathrm{~kW}$ For cooling load between $1000 \mathrm{~kW}$ to $4500 \mathrm{~kW}$, single effect is more suitable and cooling load more than that, it is advisable to be served by double effect type. Advantages of absorption chiller are environmental friendly ; using of non toxic solution as refrigerant, low investment cost, low maintenance and operation cost due to its efficiency.

In absorption chiller, usually non toxic working fluids are used such as water which studied by Garcia Cascales et al. [29] for performance analysis while Evola et al. [30] found that using saline solutions did improve more on the performance of system compared to water. Furthermore, its consistent with findings of previous study by K.F.Fong et al. [31] which using others different refrigerant by experimentally.

In fact, previous studies shown that optimization assessment of lithium bromide-water solution been developed and tested by Iranmanesh and Mehrabian [23]. Effectiveness and economical view were carried out by Bukoski et al. [32] for different kind of absorption chillers and performance compatibility studied was carried out previously by Lecuona et al. [33] for single 
effect type and while double effect type by Avanessian and Ameri [34].

\section{Hybrid air conditioning}

Hybrid system means the combination of new system to existing running system. From previous literature surveys, typically hybrid air-conditioning has been integrated and developed due to enhancement of current system which is vapour-compressor system. Since that integral energy sources has to be conserved, many ideas of hybrid system rapidly grown as concerning on energy and environmental saving factor.

Types of hybrid air conditioning are solid desiccant or liquid desiccant in vapour compression system and experimentally done by Mohammad et al. [35]. Other types of hybrid air conditioning are cascade vapour compression with absorption cycle type proposed by Jain et al. [36], solar-biomass hybrid system studied by Prasartkaew and Kumar [37] and solar absorption and vapour compression based hybrid air conditioning investigated by Ortiz et al. [38], Rosiek and Batlles [39] and Diaconu [40].

\subsection{Solar Absorption and Vapour Compression System based Hybrid Air Conditioning}

As we all known, hybrid solar absorption and vapour compression system proven for electric power saving and support for green energy utilization as taking advantages from daily solar radiation. Figure 5 presents the basic configuration of hybrid solar absorption and vapour compression system. Usually, this system can operate in two different modes independently according to current weather.

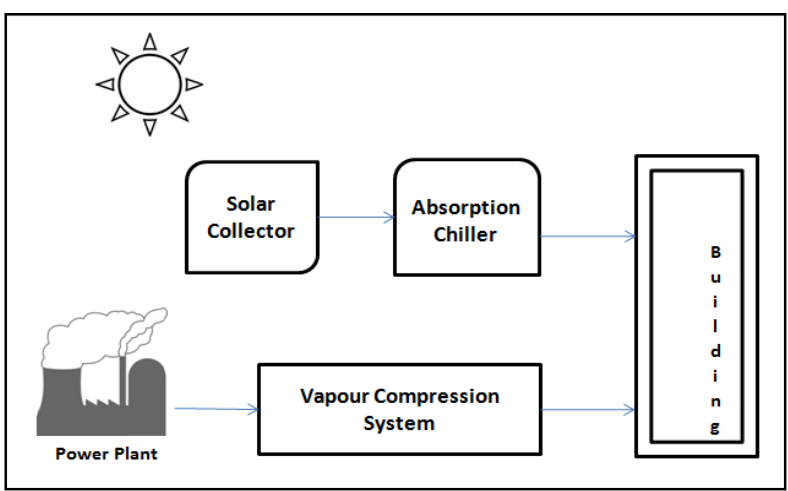

Figure 5. System configuration without low temperature storage

During sunny day, solar energy can be harvest and absorption chiller will provide cool air to building. Advantages are more usage on clean energy and reflected on energetic saving. On a contrary, during cloudy and rainy day, system depends on vapour compression system only which been supplied an electricity from power plant. Thus, this configuration contribute to greenhouse gasses to environment.

In 2010, Al-Alili et al. [41] published a paper in which they described performance analysis through modeling using TRANSYS and found that cost savings reduction up to $24.5 \%$. In spite, Syed et al. [42] did performance assessment and resulting 0.42 of COP in Madrid while other research from Brazil, Ferreira Leite et al. [43] achieved 0.6 of COP.

In summary, many interesting results coming from all around the world and suggested their operating strategies differently to suit with their local climate variation, but only little work has examined operating strategies for tropical region. Moreover, challenge of intermittence solar energy and variation in cooling demand were the main problems which present complexity of overall system.

\subsection{Solar Absorption and Vapour Compression System based Hybrid Air Conditioning with Low Temperature Storage}

Low temperature storage system are essential to overcome the disadvantages of the unstable daily solar radiation and differential in cooling demand [44]. In order to optimize solar powered air conditioning, different types of low temperature storage been proposed according to location, situation and environmental condition. Figure 6 indicates the hybrid solar absorption and vapour compression with additional of low temperature storage.

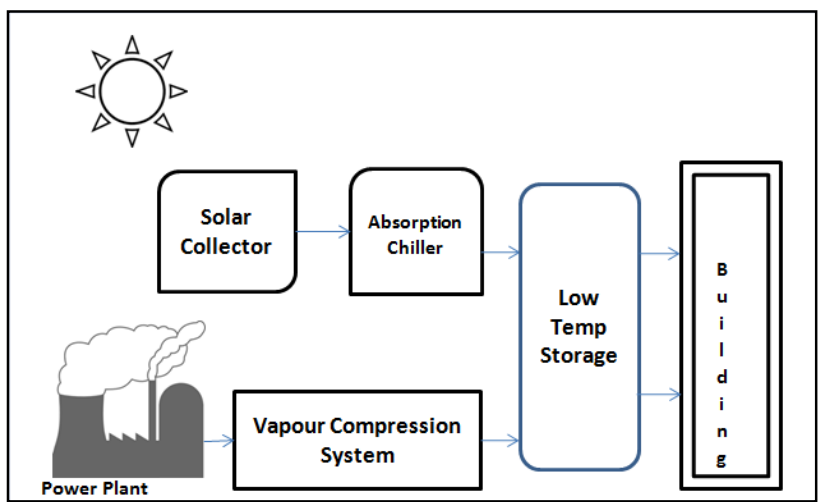

Figure 6. System configuration with low temperature storage

Low temperature storage as additional component did improve the overall system configuration in terms of economic factor as it can stored chilled water, ice storage or phase change material (PCM). During sunny day, hybrid solar absorption will fully running and low temperature storage will be operate to store energy for later use. Cool air still can be supplied to building even tough on rainy or cloudy day and less operating on vapour compression system. More economic saving can be achieved and proven of improvement from previous configuration. At such, common and simplest type of low temperature storage are chilled water storage because of its availability.

Therefore, due to the storage capability, operating strategies can be manipulated by shifting the cooling load from peak period to off-peak period. Figure 7 shows the different storage operating strategies can be adapt to hybrid solar absorption and vapour compression with low temperature storage. 


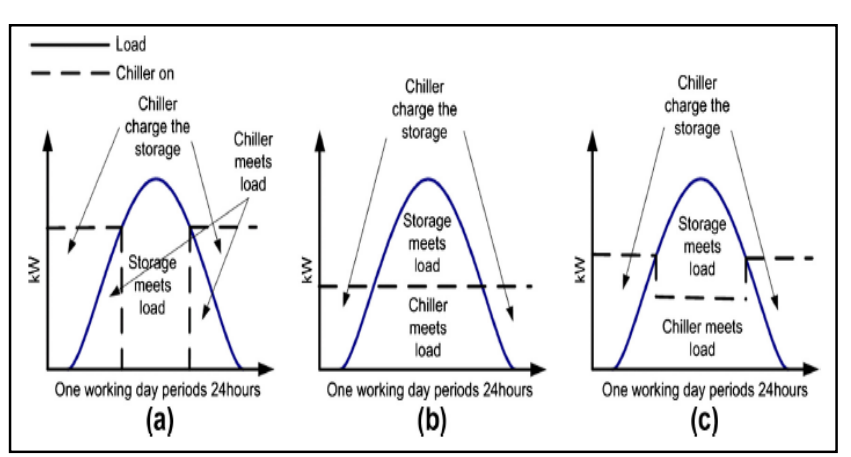

Figure 7. Schematic diagram of different storages strategies, (a) Full storage (b) Partially storage load levelling (c) Partially storage demand limiting [45]

In recent research by Lin et al. [46] evaluated that economic and thermodynamic are key factors to achieve $15 \%$ power saving from total power consumption with different operating strategies. Other studies by Al-Ugla et al. [47] done a comparative analysis for different types of storage as shown in Table 1.

Table 1. Comparative analysis of alternative design

\begin{tabular}{|l|l|l|}
\hline $\begin{array}{l}\text { Alternative } \\
\text { Design }\end{array}$ & Advantages & Disadvantages \\
\hline $\begin{array}{l}\text { Heat } \\
\text { storage }\end{array}$ & $\begin{array}{l}\text { COP of the } \\
\text { system higher } \\
\text { for nighttime } \\
\text { operation }\end{array}$ & $\begin{array}{l}\text { Absorption cycle } \\
\text { operated day and } \\
\text { night with thick } \\
\text { insulation }\end{array}$ \\
\hline $\begin{array}{l}\text { Cold } \\
\text { storage }\end{array}$ & $\begin{array}{l}\text { Absorption } \\
\text { cycle operate } \\
\text { only in daytime } \\
\text { and less } \\
\text { complexity of } \\
\text { system }\end{array}$ & $\begin{array}{l}\text { Large size } \\
\text { evaporator and } \\
\text { generator }\end{array}$ \\
\hline $\begin{array}{l}\text { LCM storage } \\
\text { storage }\end{array}$ & $\begin{array}{l}\text { strength not } \\
\text { critical, thin }\end{array}$ & $\begin{array}{l}\text { Evaporator } \\
\text { operates day and } \\
\text { night as heat } \\
\text { storage } \\
\text { insulation }\end{array}$ \\
& & alternative \\
\hline
\end{tabular}

Although the concept is very simple, various operation modes together with structure rate been studied separately by Zhang et al. to determine the optimum sizing and operating strategies [48]. However, experimental been conducted by Boonnasa and Namprakai [49] are to estimate the saving potential with different scenarios of operating strategies with retrofit chilled water storage to existing system and proved it gives saving up to $31.2 \%$ respectively. Other researchers such Yin et al. [50] does investigate different operating strategies by applied different types of cooling mode in Shanghai Jiao Tong University. They studied on solar absorption system with fan coil cooling mode and solar absorption ceiling cooling mode and summarize that system with ceiling cooling mode gave higher potential result which output increased by $23.5 \%$. On the other hand, Al-Alili et al. [51] studies effect of different collector slope on the economic and environmental assessment. They conclude that reduction of 12 metric tonne/year of $\mathrm{CO} 2$ emission and $47 \%$ of energy saving achieved as compared to conventional vapour compression system with the same cooling load.

There are few optimization method were introduced in previous literature such as using TRNSYS simulation model, artificial neural networks (ANN) and static modelling. Later, simulation performance data was verify through Root Mean Square Error (RMSE) or mean relative difference. The variable parameters were cooling capacity, COP of system, mass flow rate, incident radiation intensity, solar collector's temperature and storage tank's temperature. Hence, Rosiek and Batlles [39] investigate performance analysis and conclude that simulation values was in match to the experimental value by $0.7 \%$ RMSE error caused by the artificial neural network. Control strategy performed by Marc et al. [52] was static modelling to estimate chiller behaviour and define their operating range. This method use laboratory experimental results in actual operating strategy. Parameters involved were temperature in heating cycle, cooling cycle, chilling capacity and overall COP. These parameters and numerical results were compared to experiment data for validation and resulting 4-5\% of mean relative difference. To gain behavior of the system components and design for optimization, TRNSYS software was used to model energy and building system. Operating parameters were types of building, mass flow rate, types of storage tank and types of absorption chiller. Ortiz et al. [38] were investigate performance study and through numerical model. Their results proved that $90 \%$ of total heating requirement can be covered by solarassisted air conditioning system. On the contrary, Albers [53] was suggested simplification in numerical method by taking a few assumptions as no back up system was considered, electricity for pump was neglected, storage effect was neglected and no energetic material was considered. He concludes that with this simplification, seasonal energy efficiency ratio (SEER) is above 0.75 , electric efficiency is $35 \%$ higher and water consumption reduced by $70 \%$.

Optimization of solar collector and storage tank size can be defined by simulation model. Alva and Gonza'lez [54] were determined relationship between annual solar fraction, collector area, number of collectors and storage volume using simplified model presented by Hernandez [55]. He conclude that optimum storage volume to collector area ratio is $125 \mathrm{liter} / \mathrm{m} 2$.

Most economic low temperature storage is chilled water storage. Henze et al. [56] previously studied on economic analysis and proved cost saving up to $25 \%$ and payback period within three years. However, Rismanchi et al. [57] achieved $35 \%$ on cost saving of energy consumption.

While, (PCM) was found to be more effective as compared to chilled water system due to its special characteristics which is heat transfer rate. Research done by Diaconu et al. [58] shown that value for heat transfer coefficient of PCM were higher that water under identical temperature conditions. Others characteristics of PCM 
are thermo physical properties such as high thermal conductivity, chemical properties such as non toxic, long term stability behaviour, non corrosive and kinetics properties such as having high crystalline rate as defined by . Nowadays, there are few types of PCM been used in market place such as composite PCM, nano-composite PCM and microencapsulated PCM and all their properties were reviewed and compared by Zhai et al. [59] for further references.

However, too little attention has been paid to available operating strategies and system optimization for tropical climate condition. Furthermore, only few researches have been found to investigate on solar absorption and vapour compression based hybrid air conditioning system while considering both environmental and economic factors.

\section{Conclusion}

The review on solar absorption and vapour compression based hybrid air conditioning system indicates that many research are carried out with the purpose for continuous improvement and effectiveness. Thus, the findings from this review make several contribution to authors understanding from current literature on basic component of solar absorption vapour compression system to system optimization, energy, economic and environmental effects. Combination with renewable energy resources such as solar energy does give good results in exploratory future research on renewable energy utilization. Last but not least, further work need to be done to determine optimization of solar absorption and vapour compression system based hybrid air conditioning with low temperature storage.

\section{References}

[1] B. Choudhury, B. B. Saha, P. K. Chatterjee, and J. P. Sarkar, "An overview of developments in adsorption refrigeration systems towards a sustainable way of cooling," Applied Energy, vol. 104, pp. 554-567, 4// 2013.

[2] U. Desideri, S. Proietti, and P. Sdringola, "Solar-powered cooling systems: Technical and economic analysis on industrial refrigeration and air-conditioning applications," Applied Energy, vol. 86, pp. 1376-1386, 9// 2009.

[3] I. Daut, M. Adzrie, M. Irwanto, P. Ibrahim, and M. Fitra, "Solar Powered Air Conditioning System," Energy Procedia, vol. 36, pp. 444-453, // 2013.
[4] Q. P. Ha and V. Vakiloroaya, "Modeling and optimal control of an energyefficient hybrid solar air conditioning system," Automation in Construction, vol. 49, Part B, pp. 262-270, 1// 2015.

[5] O. Ayadi, A. Mauro, M. Aprile, and M. Motta, "Performance assessment for solar heating and cooling system for office building in Italy," Energy Procedia, vol. 30, pp. 490-494, // 2012.

[6] K. F. Fong and C. K. Lee, "Performance advancement of solar air-conditioning through integrated system design for building," Energy, vol. 73, pp. 987-996, 8/14/ 2014.

[7] Z. Li, X. Ye, and J. Liu, "Performance analysis of solar air cooled double effect $\mathrm{LiBr} / \mathrm{H} 2 \mathrm{O}$ absorption cooling system in subtropical city," Energy Conversion and Management, vol. 85, pp. 302-312, 9// 2014.

[8] X. G. Casals, "Solar Cooling Economic Considerations: Centralized Versus Decentralized Options," Journal of Solar Energy Engineering, vol. 128, pp. 231-236, 2006.

[9] A. A. Al-Abidi, S. Bin Mat, K. Sopian, M. Y. Sulaiman, C. H. Lim, and A. Th, "Review of thermal energy storage for air conditioning systems," Renewable and Sustainable Energy Reviews, vol. 16, pp. 5802-5819, 10// 2012.

[10] Absorption Refrigeration. Available: https://web.engr.oregonstate.edu/ naray avi/absorption\%20refrigeration.html

[11] WALL MOUNTED. Available: https://www.fujitsugeneral.com.au/resid ential-range/wall-mounted

[12] Wall mounted air conditioners. Available:

http://www.mitsubishielectric.com.au/w all-mounted-air-conditioners.html

[13] CASSETTE. Available: https://www.fujitsugeneral.com.au/com mercial-range/cassette-c

[14] T. M. I. Mahlia, H. H. Masjuki, and I. A. Choudhury, "Potential electricity savings by implementing energy labels for room air conditioner in Malaysia," Energy Conversion and Management, vol. 43, pp. 2225-2233, 11// 2002. 
[15] Pricing \& Tariff, Malaysia: Tenaga Nasional Berhad (TNB). Available: http://www.tnb.com.my

[16] H.-M. Henning and J. Döll, "Solar Systems for Heating and Cooling of Buildings," Energy Procedia, vol. 30, pp. 633-653, // 2012.

[17] GEO Building. Available: http://www.greentechmalaysia.my/

[18] Case Studies. Available: http://sdc.my/home.php

[19] Tenaga Boleh Baharu (TBB). Available: http://www.kettha.gov.my/portal/index. php? $\mathrm{r}=$ kandungan/index\&menu $1 \mathrm{id}=2 \&$ menu2 $\mathrm{id}=65 \&$ menu3 $\mathrm{id}=118 \#$. VeZf3y Wqqko

[20] Solar Collectors: Different Types and Fields of Application. Available: http://www.solarserver.com/knowledge/ basic-knowledge/solar-collectors.html

[21] FLAT PLATE VS. EVACUATED TUBE SOLAR HOT WATER COLLECTORS. Available:

http://www.energymatters.com.au/solarhot-water/flat-vs-evacuated/

[22] A. M. Baniyounes, Y. Y. Ghadi, M. G. Rasul, and M. M. K. Khan, "An overview of solar assisted air conditioning in Queensland's subtropical regions, Australia," Renewable and Sustainable Energy Reviews, vol. 26, pp. 781-804, 10// 2013.

[23] A. Iranmanesh and M. A. Mehrabian, "Optimization of a lithium bromidewater solar absorption cooling system with evacuated tube collectors using the genetic algorithm," Energy and Buildings, vol. 85, pp. 427-435, 12// 2014.

[24] K. Sumathy, Z. C. Huang, and Z. F. Li, "Solar absorption cooling with low grade heat source - a strategy of development in South China," Solar Energy, vol. 72, pp. 155-165, 2// 2002.

[25] Saghiruddin and M. A. Siddiqui, "Economic analysis of two stage dual fluid absorption cycle for optimizing generator temperatures," Energy Conversion and Management, vol. 42, pp. 407-437, 3// 2001.
[26] M. Z. I. Khan, B. B. Saha, K. C. A. Alam, A. Akisawa, and T. Kashiwagi, "Study on solar/waste heat driven multibed adsorption chiller with mass recovery," Renewable Energy, vol. 32, pp. 365-381, 3// 2007.

[27] K. Gommed and G. Grossman, "Experimental investigation of a liquid desiccant system for solar cooling and dehumidification," Solar Energy, vol. 81, pp. 131-138, 1// 2007.

[28] S. Arivazhagan, S. N. Murugesan, R. Saravanan, and S. Renganarayanan, "Simulation studies on R134a-DMAC based half effect absorption cold storage systems," Energy Conversion and Management, vol. 46, pp. 1703-1713, $7 / / 2005$.

[29] J. R. García Cascales, F. Vera García, J. M. Cano Izquierdo, J. P. Delgado Marín, and R. Martínez Sánchez, "Modelling an absorption system assisted by solar energy," Applied Thermal Engineering, vol. 31, pp. 112-118, 1// 2011.

[30] G. Evola, N. Le Pierrès, F. Boudehenn, and P. Papillon, "Proposal and validation of a model for the dynamic simulation of a solar-assisted singlestage $\mathrm{LiBr} /$ water absorption chiller," International Journal of Refrigeration, vol. 36, pp. 1015-1028, 5// 2013.

[31] K.F.Fong, C. K. Lee, T. T. Chow, Z. Lin, and L. S. Chan, "Solar hybrid airconditioning system for high temperature cooling in subtropicalcity," Renewable Energy, vol. 35, pp. 24392451, 2010.

[32] J. Bukoski, S. H. Gheewala, A. Mui, M. Smead, and S. Chirarattananon, "The life cycle assessment of a solar-assisted absorption chilling system in Bangkok, Thailand," Energy and Buildings, vol. 72, pp. 150-156, 4// 2014.

[33] A. Lecuona, R. Ventas, C. Vereda, and R. López, "Absorption solar cooling systems using optimal driving temperatures," Applied Thermal Engineering, vol. 79, pp. 140-148, 3/25/ 2015.

[34] T. Avanessian and M. Ameri, "Energy, exergy, and economic analysis of single 
and double effect $\mathrm{LiBr}-\mathrm{H} 2 \mathrm{O}$ absorption chillers," Energy and Buildings, vol. 73, pp. 26-36, 4// 2014.

A. T. Mohammad, S. Bin Mat, M. Y. Sulaiman, K. Sopian, and A. A. Alabidi, "Survey of hybrid liquid desiccant air conditioning systems," Renewable and Sustainable Energy Reviews, vol. 20, pp. 186-200, 4// 2013.

[36] V. Jain, S. S. Kachhwaha, and G. Sachdeva, "Thermodynamic performance analysis of a vapor compression-absorption cascaded refrigeration system," Energy Conversion and Management, vol. 75, pp. 685-700, 11// 2013.

[37] B. Prasartkaew and S. Kumar, "Experimental study on the performance of a solar-biomass hybrid airconditioning system," Renewable Energy, vol. 57, pp. 86-93, 9// 2013.

[38] M. Ortiz, H. Barsun, H. He, P. Vorobieff, and A. Mammoli, "Modeling of a solar-assisted HVAC system with thermal storage," Energy and Buildings, vol. 42, pp. 500-509, 4// 2010.

[39] S. Rosiek and F. J. Batles, "Performance study of solar-assisted airconditioning system provided with storage tanks using artificial neural networks," International Journal of Refrigeration, vol. 34, pp. 1446-1454, 9// 2011.

[40] B. M. Diaconu, "Energy analysis of a solar-assisted ejector cycle air conditioning system with low temperature thermal energy storage," Renewable Energy, vol. 37, pp. 266276, 1// 2012.

[41] A. Al-Alili, Y. Hwang, R. Radermacher, and I. Kubo, "Optimization of a solar powered absorption cycle under Abu Dhabi's weather conditions," Solar Energy, vol. 84, pp. 2034-2040, 12// 2010.

[42] A. Syed, M. Izquierdo, P. Rodríguez, G. Maidment, J. Missenden, A. Lecuona, et al., "A novel experimental investigation of a solar cooling system in Madrid," International Journal of Refrigeration, vol. 28, pp. 859-871, 9// 2005.
[43] A. P. Ferreira Leite, F. A. Belo, M. M. Martins, and D. B. Riffel, "Central air conditioning based on adsorption and solar energy," Applied Thermal Engineering, vol. 31, pp. 50-58, 1// 2011.

[44] L. A. Chidambaram, A. S. Ramana, G. Kamaraj, and R. Velraj, "Review of solar cooling methods and thermal storage options," Renewable and Sustainable Energy Reviews, vol. 15, pp. 3220-3228, 8// 2011.

[45] B. Rismanchi, R. Saidur, H. H. Masjuki, and T. M. I. Mahlia, "Modeling and simulation to determine the potential energy savings by implementing cold thermal energy storage system in office buildings," Energy Conversion and Management, vol. 75, pp. 152-161, 11// 2013.

[46] H. Lin, X.-h. Li, P.-s. Cheng, and B.-g. $\mathrm{Xu}$, "Thermoeconomic evaluation of air conditioning system with chilled water storage," Energy Conversion and Management, vol. 85, pp. 328-332, 9// 2014.

[47] A. A. Al-Ugla, M. A. I. El-Shaarawi, and S. A. M. Said, "Alternative designs for a 24-hours operating solar-powered $\mathrm{LiBr}-$ water absorption air-conditioning technology," International Journal of Refrigeration, vol. 53, pp. 90-100, 5// 2015.

[48] Z. Zhang, W. D. Turner, Q. Chen, C. $\mathrm{Xu}$, and $\mathrm{S}$. Deng, "Tank size and operating strategy optimization of a stratified chilled water storage system," Applied Thermal Engineering, vol. 31, pp. 2656-2664, 10// 2011.

[49] S. Boonnasa and P. Namprakai, "The chilled water storage analysis for a university building cooling system," Applied Thermal Engineering, vol. 30, pp. 1396-1408, 8// 2010.

[50] Y. L. Yin, Z. P. Song, Y. Li, R. Z. Wang, and X. Q. Zhai, "Experimental investigation of a mini-type solar absorption cooling system under different cooling modes," Energy and Buildings, vol. 47, pp. 131-138, 4// 2012. 
[51] A. Al-Alili, M. D. Islam, I. Kubo, Y. Hwang, and R. Radermacher, "Modeling of a solar powered absorption cycle for Abu Dhabi," Applied Energy, vol. 93, pp. 160-167, 5// 2012.

[52] O. Marc, G. Anies, F. Lucas, and J. Castaing-Lasvignottes, "Assessing performance and controlling operating conditions of a solar driven absorption chiller using simplified numerical models," Solar Energy, vol. 86, pp. 2231-2239, 9// 2012.

[53] J. Albers, "New absorption chiller and control strategy for the solar assisted cooling system at the German federal environment agency," International Journal of Refrigeration, vol. 39, pp. 48-56, 3// 2014.

[54] L. H. Alva and J. E. Gonza'lez, "Simulation of an Air-Cooled SolarAssisted Absorption Air Conditioning System," Journal of Solar Energy Engineering, vol. 124, pp. 276-282, 2002.

[55] H. Hernandez, "Analysis and Modeling of a Solar-Assisted Air Conditioning and Dehumidification System for Applications in Puerto Rico," M.S., Univ. of Puerto Rico, 1997.

[56] G. P. Henze, B. Biffar, D. Kohn, and M. P. Becker, "Optimal design and operation of a thermal storage system for a chilled water plant serving pharmaceutical buildings," Energy and Buildings, vol. 40, pp. 1004-1019, // 2008.

[57] B. Rismanchi, R. Saidur, H. H. Masjuki, and T. M. I. Mahlia, "Energetic, economic and environmental benefits of utilizing the ice thermal storage systems for office building applications," Energy and Buildings, vol. 50, pp. 347-354, 7// 2012.

[58] B. M. Diaconu, S. Varga, and A. C. Oliveira, "Experimental assessment of heat storage properties and heat transfer characteristics of a phase change material slurry for air conditioning applications," Applied Energy, vol. 87, pp. 620-628, 2// 2010.
[59] X. Q. Zhai, X. L. Wang, T. Wang, and R. Z. Wang, "A review on phase change cold storage in air-conditioning system: Materials and applications," Renewable and Sustainable Energy Reviews, vol. 22, pp. 108-120, 6// 2013. 